in Jedia $\quad \begin{aligned} & \text { InMedia } \\ & \text { The French Journal of Media Studies }\end{aligned}$

7.2. 2019

Documentary and Entertainment

\title{
Entre le jeu et le joueur : écarts et médiations
}

25-27 octobre 2018, colloque international "entre le jeu et le joueur :

écarts et médiations", Université de Liège

Thomas Dedieu

\section{(2) OpenEdition \\ 12 Journals}

\section{Electronic version}

URL: http://journals.openedition.org/inmedia/1812

DOI: 10.4000/inmedia.1812

ISSN: 2259-4728

\section{Publisher}

Center for Research on the English-Speaking World (CREW)

\section{Printed version}

Date of publication: 15 December 2019

\section{Electronic reference}

Thomas Dedieu, "Entre le jeu et le joueur : écarts et médiations", InMedia [Online], 7.2. I 2019, Online since 02 December 2019, connection on 26 January 2021. URL: http://journals.openedition.org/inmedia/ 1812 ; DOI: https://doi.org/10.4000/inmedia.1812

This text was automatically generated on 26 January 2021.

(C) InMedia 


\section{Entre le jeu et le joueur : écarts et médiations}

25-27 octobre 2018, colloque international "entre le jeu et le joueur : écarts et médiations", Université de Liège

\section{Thomas Dedieu}

1 The young age of video game as a medium or metamedium (a property that allows it to recreate other mediums) sheds light on the academic effervescence and the number of debates around it. Since the first creations by college hackers at the MIT in 1962 with spacewar!, the video game increased in popularity, becoming the very image of modern mass media, while surpassing the movie industry in terms of revenue. Video games are also at the very core of many social controversies; "traditional" media then provided a vessel for all the critics and restless popular worry vis-à-vis the supposed influence of video games with violence desensitization, damaging ideologies and general brainwashing of youth. These influences became for many the very essence of the video game. From the Columbine High School shooting to the Christchurch terrorist attack, video games are often pointed out as a factor of influence. Also devalued is the immediate aspect of the medium; immediate pleasure, immediate mastery of controls, absence of delimitations between player and avatar, which might cause said desensitization.

Game studies rise at the end of last century, even though playing and games had already been addressed by scholars such as Johan Huizinga, Roger Caillois, Donald Woods Winnicott, Jacques Henriot... Espen J. Aarseth, one of the first scholars to explore video games, describes a cybertext as a semiotic, textual structure in which the reader has an "ergodic" part and participates in the final configuration of the text one is experiencing ${ }^{1}$. Very quickly, dissension appears in the field of game studies, between the narratologists and the ludologists ${ }^{2}$. That divide soon calmed down with the realization that game studies were inherently interdisciplinary and now comprise literary studies, cinematographic studies, sociology, anthropology, psychology, ludology... Besides, the quarrel was rather artificial, since it occurred that the debates might have had more to do with the setting of game studies as an academic field than with a radical 
epistemological divide. As the narratologists favoured examining games through literary concepts and paradigms, ludologists called for the establishment of a separate field to acknowledge the specificity of their object, and today both disciplines coexist in game studies. Since, alongside game studies that focus on the structural, synchronic aspect of the study of video games, came play studies, that are devoted to the diachronic aspect of the activity of interacting with a game ${ }^{3}$. Nevertheless, these reconciliations and precisions never abolished the stereotype of immediateness that affects the video game.

From 25 to 27 October 2018, an international French-speaking conference was held at the Université de Liège, called "Entre le jeu et le joueur: écarts et médiations". It focused on the relations linking the player and the game while avoiding the traditional clichés plaguing video game as a medium, especially the characterization of video game as an immediate medium. The objective of this conference was thus to question and deconstruct this notion of inherent immediateness through theoretical considerations and field studies. Each day had its own theme, divided into three subcategories of two or three categories. More than thirty scholars from many academic institutions and professionals in French-speaking regions (Québec, France, Switzerland, Belgium) came to Liège to discuss their findings in game or play studies, with lively debates following every one of the twenty-five contributions and two keynotes.

\section{Day One: playing and engagement}

On the first day, Maude Bonenfant presented ludification ${ }^{4}$ (the use of game mechanics in order to induce behaviours in non-ludic contexts) as a language in a space of reformulation and reconstruction, codified following the possibilities of appropriation of the ludic elements. Two types of gamification are distinguished from one another: behavioural gamification (strict, based on game mechanics such as BLAP - badges, levels, achievements and points) and creative gamification (based on play mechanics). Bonenfant also put in contrast extrinsic motivation and intrinsic motivation to mobilize one's agency in the ludic context. Communication, in a ludic context and in a psychoanalytic perspective, is mediated by the tiers symbolisant ${ }^{5}$, a social interaction that puts into action a dimension both immanent and transcendant in communication; one always says something about one is saying. The principle of the Other is more open and interactive in creative gamification, which creates a hermeneutic openness in play.

The first day was thematically focused on the notion of engagement, whether academic engagement in research, mediation and appropriation by the player, or the very definition of the activity of playing. The first communication explored the notion of appropriation of the game by the researcher who reached an aesthetical interpretation of game mechanics by the player in a context of research. The researcher can appropriate the game while keeping their distances with it, in this case, a rock-metal tribute to the game Metroid allowed the interpretation of the Game Over mechanics as an intradiegetic part of the game. The second talk enumerated the various means and hindrances on the measuring of various parameters of play such as focus, eye movement and stamina while playing; it is indeed difficult to measure these parameters as if they were absolutely representative of a ludic experience by a player at home, since the fact that measuring instruments are needed and present to the player creates a self-consciousness of the playing, and prevents the phenomenon of 
immersion. The third communication delivered a hermeneutic consideration of the iconological status of image in games comprising an explicit discourse on reflexivity; in these games such as The Witness or The Stanley Parable, the image is a message in itself, presenting a perceivable space that is both navigable and restricted, which gives an image of the video game between navigation/exploration and feedback loop. The aesthetics of games can then exploit metavideoludic images that send the player back to their situation as a player.

6 The next three communications questioned the participatory aspect of video games through the activities of players that result in a modification or an extension of the game that may be recuperated by the developers of the game; through fan mail with the progressive development of a Korean educative video game used in school in which developers implemented suggestions made by young players by mail, through fan art or fan fiction in the case of Overwatch folklore, or through modding (the act of using the source code of a game to either modify it or create a new game) with the Half-Life series, which can result in totally different experiences (a Half-Life mod, Counter Strike, is now a successful franchise offering a radically different first-person shooter experience).

The third set of communications defined play as a complex practice. It first shed light on alternative playing practices such as non-play; some players (or non-players) subvert the game in a way that is not intended by the developers in player projects such as Dead in Iraq which subverts the experience of American Army by giving in a propaganda game the names of soldiers dead in Iraq, or Far Lands, where a player documents itself walking in Minecraft towards the "end of the map" (which is procedurally generated). The second speech elaborated on the two strategies at play in the Pokémon Go communities, legit play and fly play ; players can indeed trick the game into recording GPS movement that is not performed by the players, allowing them to directly go to strategically advantageous points in the game without walking, which is received with various reactions in the community of players. The last presentation was devoted to the witnessing of one's own learning in games such as The Witness, a game where the player must learn and crack codes and puzzles in order to progress, and on how to visualize the learning experiences made by the player in order to account for the different deviations and mediations of different players in the interpretation of the game. The day closed on a visit of the Digital Lab, a laboratory of research and experiments on video games and a place of digital mediation for the public.

\section{Day Two: playing instruments; display, peripherals, corporeality}

8 The second day was devoted to the instruments of game, play or gameplay. Sébastien Genvo gave a keynote in which he stressed out the importance of emphasizing play design over game design, thus focusing on the experience made by the player. To be persuasive or expressive, a game must convey a shared meaning of playing to the player. By conveying this meaning through ludic markers and, the player can produce an rational or emotional interpretation of the interactive story by acting following a ludic ethos. Genvo illustrated his keynote by examples of creative research: Keys of a Gamespace $^{6}$, a game made around a situation that is scarcely open to gamification (the story of the game revolves around paedophilia), in which the choices of the player will build an ethos that will live on after the ludic experience. While discussing his next 
project, Lie in My Heart ${ }^{7}$, Genvo enunciated the principle of play design; to build an openness to interpretation in a Winnicottian space ${ }^{8}$, that is not psychic reality nor outside world.

The speeches of the first part of the second day called for a finer definition of the concept of peripheral devices and displays through a comparison between musical instruments and controllers (especially between the practising of ranges and the kinetic, in-game practising of kinetic mastery of the game during the play on an ontological and a teleological plane), a review of the utilitarian notion of peripheral devices in playing that are available and adequate, contradicted by the existence of hindering peripheral devices and subversive practices, and a final communication on the incorporation of peripheral devices and controllers in competitive gaming and esport, proposing new frames of observation of gaming practices in the field of institutionalized competitions.

The second part featured three communications on paratext and visual display such as the on-screen head-up display, either by analysing the evolution of the production of the paratextual space in order to identify an epi-iconic and inter-iconic aspect of the illustration in survival-horror games (images that link the content of the game to horror genres at the risk of iconic aridity), by observing the metaleptic inclusion of simulated digital displays in "interfacial games" such as Emily Is Away, or by questioning the essentializing general characterization of the cultural productions that are often simply named "JRPG" (Japanese role-playing game), favouring the character sheet (a set of quantifying values allowing the visualization of the avatar) as a criterion of generic classification in role-playing games.

The last part of the second day focused in its first communication on the evolution of the -omnipresent and polysemic in gaming - notion of exploration through philosophy and discourse analysis, before an address on the history of the imaginary camera in games, an aesthetic process that became "lexicalized" in video games (so much that point of view and camera are often confused with one another), to close the day on a last talk reviewing the use of binaural sound, vocality and camera in Hellblade: Senua's Sacrifice and concluding on the creation of intermediary and homeostatic (selfsustaining through feedback loops) realities by creating instances such as intradiegetic vocal guides.

\section{Day Three: cultural mediations of the (video) game; intermediary spaces in play and games}

The final day was dedicated to the cultural and intercultural mediations of the game and the video game in intermediary spaces. The first two communications presented case studies of experiments of game as a cultural mediator or as a tool for cultural and digital mediation: in the first case, the contribution presented an interfacial video game integrated as a cultural mediator in a digital museum experience in the Mucem (Marseilles); it was then studied as an intermediary mediator in its production and reception. In the second case, an educator introduced a game design workshop used as a cultural mediator with young people using game design as a practice of selfdescription as gamers, but also as a means of teaching discursive expression through the rhetoric tools of video games. 

game, on the side of reception. The first speech explored the history of distribution networks of domestic video game in France between 1975 and 1995, from a period of importation to a reorganisation of the console market, without forgetting the role of the French industry from 1983, whose creation is greatly caused by an active part of the distributors that assumed both the selling and developing of games. The second talk addressed the figure of the "noob journalist" with the humiliation of Dean Takahashi, a journalist who tested the game Cuphead, acknowledging his lack of skills in said game. The public reacted by turning the self-depreciating evaluation of the game into a public ad hominem humiliation. This attack campaign was fuelled by remnants of the infamous \#gamergate, which revealed a general hatred for video game-related press. The third address elaborated on the evolution of Japanese arcades and how Japanese public perceives them. The arcade is still in Japanese modern media a source of nostalgia and is explored by a few scholars in Japanese academia. The arcade also serves as a mediation between players, since communication notes (little notepads originally destined to provide feedback on the arcade), are turned into a social network by the customers who write or draw in them for other customers. The communication concluded on the lack of Western works on arcade that would be centred on the social aspects of theses spaces. but from the perspective of production: the first talk explored the difficulties of translation work in the context of virtual reality (VR). Translators often work in written documents without access to the game, thus ignoring the ludoconative function of the text, which allows for the player's orientation in the game by reading the text; since a fault translation prevents the player from understanding what has to be done, said player cannot progress in the game. The last talk then addressed the specificity of work ethics in online games towards a creative audience. In this context, professionals realize that users also produce content by appropriation of their work; the designers then work as engineers of a world of which the players take control. Game designers defend a part of their creative power, arguing that they know what users want better than the users themselves, while players set their will forth; a mediation is here necessary, to acknowledge the two poles in order to conciliate them, for example through community management.

The congress concluded on the importance of recognizing the richness of mediations at work in the many spaces of video game. It also revealed the fragility of the experience of play that cannot be so self-conscious that it escapes the ludic dimension of playing a game but at the same time must keep away from immediateness at the risk of eluding many philosophical, hermeneutic and aesthetical aspects of said experience. Even though the speeches and debates were dense in concepts and notions, they were a perfect example of how game and play must be taken seriously.

The debates and most speeches were either broadcast on Twitter with the hashtag \#ULiegeJV18 or uploaded on YouTube, on the Liège Game Lab channel' ${ }^{9}$. 


\section{NOTES}

1. See: Espen J. Aarseth (1997), Cybertext: Perspectives on Ergodic Literature, Baltimore (MD): The Johns Hopkins University Press.

2. See: Jan Simmons (2007), "Narrative, Games, and Theory". In Game Studies, vol. 7, issue 1. Retrieved from http://gamestudies.org/07010701/articles/simons.

3. Matthieu Triclot (2011), Philosophie des jeux vidéo, Paris : Zones.

4. About the notions of gamification, ludification and ludicization, see Maude Bonenfant and Sébastien Genvo (2014), "Une approche située et critique du concept de gamification". In Sciences du jeu,2 (online). DOI: $10.4000 /$ sdj.286.

5. Bonenfant, Marc Ménard, André Mondoux et Maxime Ouellet (2015), "De l'identité à l'identification. La dérive du tiers symbolisant". In Maude Bonenfant and Charles Perraton, Identité et multiplicité en ligne. Québec: Presses de l'Université du Québec.

6. Available at http://www.expressivegame.com/key-of-a-gamespace/, consulted on April $4^{\text {th }}$, 2019.

7. Available at http://www.expressivegame.com/lie-in-my-heart/, consulted on April $4^{\text {th }}, 2019$.

8. The cultural experience indeed happens in a space that is not the psyche of the individual nor the real world. See: Donald Woods Winnicott (1975), Jeu et réalité. L'espace potentiel, translated by Claude Monod and Jean-Benoît Pontalis, Paris, Gallimard (coll. "Folio Essais").

9. https://www.youtube.com/watch?

$\mathrm{v}=$ PKXVR6UhEQA\&list=PLmkSeQlb25sbhS2LviLeAssTns0Kv_mAF

\section{AUTHOR}

\section{THOMAS DEDIEU}

Doctorant en langues, lettres et traductologie, chercheur au centre Globalit/ISPOLE et au Laboratoire Jeux et Mondes Virtuels, Université catholique de Louvain. 